\title{
MÚLTIPLOS ATORES, MÚLTIPLOS INSTRUMENTOS: A LEGITIMAÇÃO DO PODER RÉGIO EM PORTUGAL NO GOVERNO DE D. JOÃO II (1481-1495) E D. LEONOR (1481-1525)
}

\author{
MULTIPLE ACTORS, MULTIPLE INSTRUMENTS: THE \\ LEGITIMATION OF THE REAL POWER IN PORTUGAL IN THE \\ GOVERNMENT OF D. JOHN II (1481-1495) AND D. LEONOR
}

(1481-1525)

André Costa Aciole Silva

Instituto Federal de Educação, Ciência e Tecnologia de Goiás

Resumo: Este artigo tem o objetivo de apresentar como, por meio de palavras, imagens e de uma política de atenção aos enfermos do reino, materializada na construção dos hospitais régios, os monarcas D. João II e sua consorte D. Leonor, pretenderam instrumentalizar a memória e desenvolver um cabedal de aparelhos a argumentos que possibilitou a legitimação do poder régio no Portugal tardo-medieval. Para tanto destacamos o caso do Hospital de Nossa Senhora do Pópulo, fundado por D. Leonor, por volta de 1484 , na região de Óbidos.

Palavras-chave: Legitimação. Poder régio. Hospital de Nossa Senhora do Pópulo.
Abstract: This article aims to present how, through words, images and a policy of care for the sick of the kingdom, materialized in the construction of royal hospitals, the monarchs D. João II and his consort D. Leonor, tried to instrumentalize memory and to develop an apparatus leather with arguments that made possible the legitimization of the regal power in late medieval Portugal. For this, we use the case of the Hospital of Our Lady of Pópulo, founded by D. Leonor, around 1484, in the Óbidos region.

Keywords: Legitimation. Regal power. Hospital of Our Lady of Pópulo. 
Tantas vezes apresentou-se o processo de centralização político da monarquia portuguesa como algo marcado por urdiduras palacianas, por acordos políticos, conflitos armados e pelo uso da força e da violência. É certo que esses aspectos foram mecanismos desse projeto. Mas não só. Há que se considerar a existência e uso de outros instrumentos que corroboraram para tanto e que apontaram diretamente para uma estratégia que visava a promover a legitimação do poder real e a demarcar seus espaços de atuação. Durante o governo de D. João II (1481-1495), e de sua consorte D. Leonor (1482-1525), podemos observar bem tal situação quando tratamos das formas de instrumentalização da memória promovida por meio do uso dos discursos narrativos (as crônicas), das imagens e símbolos associados aos monarcas. Ao mesmo tempo, tal projeto pode ser bem observado ao nos depararmos com uma tendência dos monarcas em atuar na criação de hospitais régios de Lisboa (Hospital de Todos os Santos) e no caso do Hospital de Nossa Senhora do Pópulo, no termo de Óbidos, donde será criada a vila das Caldas da Rainha.

\section{A memória, as crônicas e os predicados dos monarcas}

Considerando tal projeto, de legitimação do poder real, um dos lugares de atuação dos agentes políticos em destaque pode ser encontrado no uso da memória.

A reflexão sobre a relação entre memória e história nos permite afirmar que é possível observar que, naquele recorte espaço-temporal e com o interesse dos monarcas, promoveu-se o uso político da memória.

Mas aqui podemos questionar: a memória pode ser instrumentalizada para atender a interesses particulares de indivíduos, ou mesmo de grupos, ou, ainda, pode ser apenas individual? Para Maurice Halbwachs, a memória individual vincula-se a lembranças que só existem em sua relação com a memória coletiva. Nesse sentido, o autor considera que "nossa" lembrança pode apoiar-se não somente em "nossa" lembrança como também na dos "outros". "Nossas" lembranças permanecem, assim, coletivas mesmo em se tratando de acontecimentos os quais particularmente nós nos envolvemos ou mesmo quando tratamos de objetos que só nós vimos. Isso acontece porque temos sempre conosco, e em nossa memória, uma quantidade de pessoas que se ligam a nós relacionalmente ${ }^{1}$.

\footnotetext{
${ }^{1}$ HALBWACHS, Maurice. A memória coletiva. São Paulo: Vértice, 1990, p. 26.
}

\section{0}


A memória histórica, que alguns consideram também a oficial e que parece estar acima das memórias individuais e coletivas, é a responsável por promover um enquadramento dessas últimas, selecionando aquelas que devem ser valorizadas e aquelas que dever ser silenciadas ou esquecidas. Trata-se, sob nossa perspectiva, de uma estratégia de poder e de manipulação do imaginário, ao mesmo tempo das memórias individuais e coletivas com um determinado fim. Michael Pollak chamou nossa atenção não só para a memória que deve ser perpetuada como também para o que deve ser esquecido. Apagar o passado, ou tentar promover o esquecimento acerca de parte dele, sem sombra de dúvidas, é muito menos o produto de um esquecimento "natural" do que de um trabalho de gestão da memória segundo as possibilidades de comunicação²

A partir deste debate, ou seja, da relação entre história e memória, é que se pretende abordar o tema e objeto desta análise: como vários instrumentos, inclusive a edificação do Hospital de Nossa Senhora do Pópulo, serviram ao ímpeto centralizador da monarquia. Ao identificar essa intensa proximidade entre história e memória, acreditamos que os registros legislativos, dos cronistas, os espelhos de príncipes, a heráldica, entre outros, contribuíram profundamente para a constituição de uma imagem legítima acerca dos monarcas e da autoridade real. Entendemos que o projeto de fortalecimento do poder real se realizou, também, no campo da memória, uma vez que direcionada, como foi, contribuiu para a legitimação e justificação do poder. Trata-se de uma gestão da memória por meio de imagens, de ações intencionais da monarquia em seu favor.

Paul Ricoeur já demonstrou como esta memória instrumentalizada estrategicamente serve de mecanismo de construção de uma identidade tanto coletiva quanto pessoal. Para o autor, as manipulações de memória se devem ao fenômeno da ideologia, e o que esta pretende legitimar é a autoridade do poder ${ }^{3}$. Relacionado a isso, qualquer forma de poder, deve pretender-se legitimar possibilitando assim que alguém seja obedecido. São vários os instrumentos utilizados para tornar crível a ideia de que aquele (indivíduo ou representante de uma instituição) deve ser obedecido.

A legitimação do poder ou da autoridade passa pela construção da identidade (pessoal ou coletiva), e para o autor constituir identidade conduz a um mecanismo operatório da ideologia, que é a manipulação de memória através, por exemplo, da função

${ }^{2}$ POLLAK, Michael. Memória, Esquecimento, Silêncio.Estudos Históricos. Rio de Janeiro: v. 2, n.3, 1989. p. 13.

${ }^{3}$ RICOEUR, Paul. A memória, a história, o esquecimento. Campinas: UNICAMP, 2007, p. 96.

\section{1}


narrativa. Nas palavras de Ricoeur, que nos apresenta de maneira mais clara as relações entre memória e narrativa, a memória é incorporada à constituição de identidade por meio da função narrativa. A ideologização da memória torna-se presumível pelos expedientes de alteração oferecidos pelos afazeres da configuração narrativa. E, como os personagens da narrativa são postos na trama concomitantemente à história narrada, essa configuração narrativa contribui para modelar a identidade dos protagonistas e, ao mesmo tempo, os contornos da própria ação. Daí a razão de porque, nas crônicas régias, por exemplo, haver sempre a necessidade de uma contextualização inserindo o(s) monarca(s) num panorama maior que possibilita a explicação e justificativa de suas ações. É isso que permite que uma ação ou medida seja entendida como positiva, tendo sempre como referência os padrões de bom, justo e correto da época.

Deste modo, é precisamente o emprego da ação seletiva da narrativa que oferece à manipulação uma conveniência e os elementos de uma tática habilidosa que incide, a princípio, numa estratégia tanto do esquecimento quanto da rememoração. É no plano em que a ideologia atua como discurso justificador do poder, da dominação, em que se observam movimentados os recursos de mecanismos que a narrativa proporciona. Daí podemos entender que a dominação - e o reforço do poder real - não se limitam à repressão física. Inclusive um déspota impiedoso carece de um retórico, de um sofista, para decompor em discurso sua campanha de atração e intimidação. Assim, a narrativa outorgada se torna o utensílio excepcional dessa dupla intervenção ${ }^{4}$.

Para o caso de vários reis portugueses do período abordado, ou seja, do final da Idade Média, o uso da prosa por meio da construção de uma literatura cronística foi de fundamental importância para propagandear o poder real, assim como constituir uma imagem de um monarca poderoso que possui autoridade e deve ser obedecido.

O memorial histórico dos reis de Portugal, visíveis nas obras dos cronistas escolhidos pelos monarcas e materializado em imagens, deve ser pensado e lido considerando que se trata de uma memória escrita e visual, mas especialmente de uma memória modelada ao sabor da vontade e do querer de quem encomendou. As crônicas escritas estavam, sem sombra de dúvidas, a serviço de elogio de modelos de governação e dos valores da cristandade. Muitas das referências contemporâneas feitas aos monarcas,

\footnotetext{
${ }^{4}$ RICOEUR, Paul. Idem ... p. 98.
}

\section{2}


em especial a D. João II e D. Leonor, soam como panegíricos. Mas não nos esqueçamos que era esta, enfim, a razão de ser das crônicas quatrocentistas e quinhentistas.

Vale destacar, ao mesmo tempo, o papel destas narrativas como construtoras de uma fundamentação ideológica do poder real. Desde o século XIII, pelo menos, o uso de determinadas expressões e imagens vinculadas aos monarcas tem essa função. José Manuel Nieto Soria nos apresentou as imagens sacralizadoras assim como as moralizadoras construídas em Castela, mas que pode também ser identificadas aqui ${ }^{5}$. A imagem de D. João II como o Príncipe Perfeito se associa ao modelo do rei completo: cristianíssimo, piedoso, bondoso, generoso, justo, entre outros.

Estes não são títulos ostentados pelo monarca, mas são o modelo do qual o rei deveria ser a imagem, o modo como ele deveria ser descrito e visto na posteridade. Manuela Mendonça lembra-nos, inclusive, que foi depois da morte do monarca que nasce, de fato, o título de Príncipe Perfeito ${ }^{6}$.

É com a morte de D. João II que fica disseminada a ideia de que a construção da alegoria do Príncipe Perfeito, soberano de todos os predicados políticos e humanos do príncipe da Renascença, foi, sobretudo, arquitetada pela sábia imaginação popular, que foi, por sua vez, manipulada pelos cronistas. São as imagens e as crônicas as responsáveis por consolidar a representação do Rei Político, do Estadista, do Homem da Governança - e aqui está o Rei Total, o Homem de todos os predicados: bom porque soube amar o seu povo, adotando na divisa do pelicano o acabado significado da paternidade política ${ }^{7}$.

Ao mesmo tempo em quem estamos identificando o papel dos predicados e das figuras de linguagem nestes relatos cronísticos importa compreender o que significava para os homens da Idade Média estas narrativas e crônicas. A realeza, conhecedora das suas prerrogativas correspondentes a seu estado e na tentativa de consolidar-se como um poder acima de outros poderes (tanto os poderes locais, como na relação com a Igreja, um poder supranacional), também usufruía do que atualmente compreende-se como capital simbólico. De acordo com Pierre Bourdieu, a posição de um determinado agente no ambiente social pode também ser determinada pela posição que ele toma em

\footnotetext{
${ }^{5}$ SORIA, José Manuel Nieto. Imágenes sacralizadoras. In: Fundamentos ideológicos del poder real em Castilla (siglos XIII-XVI). Madrid: Eudema, 1988, p. 78.

${ }^{6}$ MENDONÇA, Manuela. D. João II : um percurso humano e político na génese da modernidade em Portugal. Lisboa: Ed. Estampa, 1995, pp. 467 - 470.

${ }^{7}$ MENDONÇA, Manuela. Idem ... p. 469.
}

\section{3}


diversos campos. Quer dizer, deve-se observar sua posição na repartição dos poderes que operam em cada um deles, seja, sobretudo, o capital econômico, o capital cultural, o capital social e também o capital simbólico, geralmente chamado prestígio, reputação, fama, entre outros ${ }^{8}$.

No período trabalhado, não havia esta sistematização em torno dos conceitos relacionados ao que Bourdieu chamou de capital simbólico. Entretanto, isso também não que dizer que este instrumental não era utilizado. Pelo contrário, como vemos no caso em estudo, esses símbolos foram forma de identificação e de definição de hierarquias. Le Goff nos esclarece esta questão ao afirmar que a Idade Média ignorou os termos símbolos, simbolismo, simbólico, no significado em que os aplicamos hoje. Symbolum não era utilizado, na Idade Média, pelos eclesiásticos senão em acepção muito particularizada e circunscrita de artigo de fé. O palco semântico do símbolo foi, essencialmente, tomado pelos termos signum, o mais próximo do nosso termo símbolo, mas também figura, imago, typus, allegoria, parabola, similitudo, speculum que definem, não obstante, um aparelho simbólico muito característico9 .

As relações de força fundadas dentro da sociedade medieval caracterizavam-se não só pela posse de bens materiais, mas também pelas representações e práticas socialmente reconhecidas e juridicamente garantidas. $O$ processo de centralização do poder político, levado a cabo em fins do século XV e início do XVI, foi de fundamental importância na disseminação de determinadas imagens e noções ligadas ao poder régio.

É dentro desta perspectiva que vamos compreender que os livros escritos ou encomendados pelos monarcas da dinastia de Avis, as Crônicas, nos podem oferecer exemplos da construção simbólica do poder régio. Ainda que estas obras cronísticas não sejam fontes essenciais a este trabalho é importante ficar claro que foram instrumentos que compunham parte do arsenal persuasivo utilizado para fazer ver que D. João II fora o príncipe perfeito e D. Leonor a mais perfeita rainha. Assim as crônicas podem servir como um exemplo da caracterização do poder simbólico dos monarcas.

De fato, percebemos claramente que a ideia de poder real acima de outros poderes também transcorria por uma exterioridade abstrata, por meio de uma manipulação dos imaginários, uma vez que estas narrativas serviam de justificativa para a superioridade do

\footnotetext{
${ }^{8}$ BOURDIEU, Pierre. O Poder Simbólico. Rio de Janeiro: Bertrand Brasil, 2001. p. 134.

${ }^{9}$ LE GOFF, J. Para um Novo Conceito de Idade Média - Tempo, Trabalho e Cultura no Ocidente. Lisboa: Ed. Estampa, 1993. p. 326.
} 
poder real, cercado de simbologia e prestígio. Mesmo sendo estes valores simplesmente simbólicos, a importância social que tinham eram imprescindíveis em um mundo assaz hierárquico como o medieval ${ }^{10}$.

\section{A heráldica na legitimação do poder régio}

Neste sentido, qualquer que fosse $\mathrm{o}$ projeto de construção de memória, especialmente como forma de afirmação legitimadora do poder régio, tal projeto levava ao empenho de múltiplos atores e múltiplos instrumentos. De modo geral, o estatuto social privilegiado do monarca precisava ser expresso exteriormente. Recorreu-se a símbolos e emblemáticas que anunciavam e manifestavam o lugar dos monarcas. Compuseram-se e divulgaram-se os signos de identificação do poder real. Com eles, tinha-se o objetivo de estabelecer uma relação do rei com seus reinos e senhorios como, ao mesmo tempo, do rei com a comunidade. Brasões, pendões, escudos, coroas, empresas e uma titulatória real são responsáveis por codificar e representar as relações de hierarquia presentes na corte e para a sociedade portuguesa ${ }^{11}$.

Tratando-se da monarquia portuguesa, do final dos quatrocentos e início dos quinhentos, o recurso das insígnias podem ser bem analisados devido à constituição de uma chancelaria régia desenvolvida precocemente caso seja comparada com outras casas reais europeias. É, também, por meio destas insígnias que o monarca projeta a visão de si pela palavra escrita, ou pela imagem simbólica, apresentando a sua diferença, e seu lugar, dentro da dinastia que fazia parte, assim como no seio da sociedade baixo medieval portuguesa.

O debate acerca dos usos da memória, feito anteriormente, serve para que possamos compreender que, para o reforço e legitimação do poder político da monarquia, foram instrumentalizados uma série de mecanismos e, na gênese do Hospital de Nossa Senhora do Pópulo, está esta vontade. O hospital em destaque é, inclusive, um destes instrumentos. Ao edificar estes hospitais, do tipo moderno em Lisboa e no termo de

\footnotetext{
${ }^{10}$ NASCIMENTO, Renata Cristina de Sousa. Os privilégios e os abusos da Nobreza em um período de transição: o reinado de D. Afonso V em Portugal (1448-1481). Tese de doutoramento (policopiada). 2005. Curso de pós-graduação em História da UFPR. p. 85.

${ }^{11}$ COELHO, Maria Helena da Cruz. Memória e propaganda legitimadora do fundador da monarquia de Avis. In: NOGUEIRA, Carlos (org). O Portugal Medieval: Monarquia e Sociedade. São Paulo: Alameda, 2010, p. 66.
}

\section{5}


Óbidos, em zona rural e local sem habitação, diga-se de passagem, D. Leonor e D. João II pretendem evidentemente consolidar, junto a toda a gente, uma imagem positiva de si.

O próprio Hospital de Nossa Senhora do Pópulo foi um meio e ambiente propagandístico dos monarcas. Por serem locais de acolhimento dos mais necessitados e de cura dos "pobres enfermos" os hospitais edificados, nas Caldas da Rainha e em Lisboa, consolidam e materializam as mensagens difundidas pela propaganda real com o uso das imagens em especial aquelas ligadas à heráldica.

Não pretendemos aqui aprofundar a discussão acerca da relação entre heráldica e poder régio, já bem tratada por Priscila Aquino Silva ${ }^{12}$. Entretanto, importa destacar alguns aspectos desta relação de modo que possamos entender o lugar do Hospital de Nossa Senhora do Pópulo dentro deste projeto maior de afirmação e legitimação do poder real.

Em primeiro lugar importa destacar o lugar da heráldica. Segundo a definição de Luiz Strubbs Saldanha Monteiro Bandeira e Gastão de Mello de Matos a heráldica ordena e organiza uma série de princípios que acondiciona as formas que precisam simbolizar episódios de ordem histórica que parece apropriado perpetuar ${ }^{13}$. Desta forma, além de a heráldica ser esta "ciência" que tem por objeto de estudo as armas, cores e emblemas que estão associados a certas pessoas e famílias, também tem como objetivo compreender esta memória que se pretende deixar marcada. Na heráldica, os símbolos exteriores são instrumentos para a construção de memória. Aqui nos importa destacar as imagens heráldicas associadas ao casal régio (D. João II e D. Leonor) presentes no Hospital de Nossa Senhora do Pópulo.

Então nos perguntamos: quais são as imagens escolhidas para identificar o casal régio? São as empresas ou divisas ${ }^{14}$ que identificam os mesmos, ou seja, o pelicano e o rastro.

\footnotetext{
${ }^{12}$ Ver capítulo V da tese de: SILVA. Priscila Aquino. O Príncipe Perfeito e a Saúde do Reino (Portugal século XV). Niterói: Programa Pós-Graduação em História da Universidade Federal Fluminense. Tese de doutorado em História (policopiada). 2012. pp. $201-240$.

${ }^{13}$ BANDEIRA, Luiz Strubbs Saldanha Monteiro. e MATOS, Gastão de Mello de. Heráldica. Lisboa: Ed. Verbo, 1969.

${ }^{14}$ Em uma outra obra que trata da heráldica portuguesa, Luiz Strubbs Saldanha Monteiro Bandeira define o que são estas empresas ou divisas. Segundo o autor, empresas ou divisas são exatamente estes ornamentos exteriores formados por desenhos heráldicos que carregam a intenção de fazer lembrar escolhida pelo autor a quem está associado. É, portanto, uma imagem (pública) que está relacionada com certo individuo (pessoa) com o objetivo de definir seu lugar, no espaço e na sociedade pretendendo ser lembrado (memória). Ainda segundo o mesmo autor a divisa pode ser completa ou incompleta. A primeira - a divisa completa é composta por uma imagem e por um mote (legenda) explicativo, enquanto a segunda - a divisa incompleta
} 
No caso do rei D. João II o pelicano é sua divisa. No período medieval, considerando as imagens difundidas pelos bestiários, o pelicano era tido como uma ave nobre que, em caso de não haver encontrado alimento para suas crias famintas, bica o próprio peito para alimentá-los e salvá-los. Também assume a alegoria do eremita uma vez que associado à passagem bíblica do livro dos Salmos 101: 7: "Tornei-me como o pelicano no ermo". Ao mesmo tempo era uma metáfora do próprio Cristo que sendo o criador de tudo e todos, para salvar a humanidade, entrega-se para morrer na cruz e redimir toda a criação. O sentido político que o pelicano assume é o que nos importa destacar. A imagem do pelicano lida desta maneira, deixa transparecer os sentidos da proteção e do paternalismo. É o rei protetor e o pai do povo que a imagem evoca.

Mas há ainda outra observação a ser feita e trata-se do mote, ou legenda, associada à imagem do pelicano. Muitas vezes, em conjunto com a figura do pelicano aparece a frase: "Pola lei e pola grei", como podemos observar na imagem que consta na reimpressão da "Crônica de El-Rey D. João II' de Rui de Pina. Aliás, o mesmo cronista, apresenta, em seu texto, uma variação da legenda, mas que não altera seu significado politico: "Por tua ley e por tua grey"15. A palavra grey é definida por Bluteau como rebanho ou ainda: "Figuradamente fe diz dos povos, porque os princepes fão feus Paftores, \& das almas, porque tem por Paftores os curas, \& Bifpos(...)"16.

Desta forma, e lidas em conjunto, fica expresso o sentido máximo de um rei paternal e caridoso. Um rei que foi também protetor e, ao mesmo tempo, justo e juiz. Por último, uma novidade, indício importante da muitas transformações pelas quais passa Portugal no entardecer da Idade Média: a noção ampliada de povo. É um rei que governa por sua lei (que não deve ser entendida como exclusivamente a vontade pessoal do monarca) e por seu povo em favor dele ${ }^{17}$.

- é identificável apenas um destes elementos. Ver: BANDEIRA, Luiz Strubbs Saldanha Monteiro. Vocabulário Heráldico. Lisboa: Mama Sume, 1985.

${ }^{15}$ PINA, Rui de. Crônica de El-Rey D. João II. Coimbra: Ed. Atlantica, 1950, p. 64.

16 Veja definição "Dicionário Portuguez \& Latino" de Raphael Bluteau. Disponível em: <http://www.brasiliana.usp.br/pt-br/dicionario/1/Grey> Acesso em 15/11/2015.

${ }^{17}$ Como dissemos não pretendemos aprofundar o debate sobre o simbolismo da empresa de D. João II por já ter sido bastante trabalhado por vários historiadores. Destacaremos a dissertação de Mestrado apresentada ao Programa de Pós-Graduação em História da Universidade Federal Fluminense de Priscila Aquino Silva intitulada: "Entre Principe Perfeito e o Rei Pelicano: os caminhos da memória e da propaganda politica através do estudo da imagem de D. João II (século XV)", disponível em: < http://www.historia.uff.br/stricto/teses/Dissert-2007_SILVA Priscila_Aquino-S.pdf >Acesso em 10/09/2013. Além deste belo trabalho mais três outros artigos nos ajudam a compreender melhor esta simbologia: COELHO, Maria Helena da Cruz. O Senhor do Pelicano, da Lei e da Grei.; PRETO, Jorge. A empresa do Príncipe Perfeito.; VENTURA, Margarida Garcez. Apontamentos para um sistema de 
Para o caso da rainha $\mathrm{D}$. Leonor, também já foram realizados vários trabalhos que envolvem sua divisa. Entretanto, ainda que vários heraldistas e historiadores tenham se debruçado sobre a mesma, parece ainda não haver consenso no que se trata das origens ou dos motivos que teriam levado a rainha escolher sua empresa. De uma banda temos um grupo de estudiosos que identifica na empresa uma rede de pesca de camarões - o camaroeiro ou camarolico ${ }^{18}$. Segundo os que defendem esta interpretação, a imagem foi escolhida pela rainha para lembrar o fatídico episódio da morte do príncipe herdeiro D. Afonso, em Santarém, e que teve seu corpo amparado por pescadores em uma rede de pesca de camarões. Tratava-se de uma forma de rememorar este episódio, mas também de elevar os valores associados à solidariedade presente no apoio dado por simples pescadores à figura do príncipe herdeiro.

De outro lado, há os que sustentam que a imagem simboliza o rastro, (que era utilizado para a pesca de arrastro) e que tal imagem fazia referência aos direitos de renda da pesca que a rainha possuía. Segundo João Bernardo Galvão-Teles e Miguel Metelo de Seixas, a interpretação da divisa como sendo o camaroeiro decorre do imaginário que se construiu em volta da rainha por conta de sua devoção e da imagem da mãe ferida em seu amor pela morte de seu filho único. Segundo os pesquisadores, a imagem é mesmo um rastro inclusive porque existem indícios do uso da mesma imagem pela rainha antes do episódio da morte de seu filho, D. Afonso. De acordo com afirmações dos autores, o rastro escolhido por D. Leonor é uma menção ao reino dos céus presente no Evangelho de Mateus, que parece ter sido o evangelista de maior afeição da rainha ${ }^{19}$. Ainda nesta linha de entendimento, a imagem do rastro tem seu entendimento completo quando ligado ao seu mote (ou alma) presente em uma pia de água benta do Convento Madre de Deus onde se lê a inscrição em latim: "Preciosior est cumctis opibus" - É mais preciosa que todas as riquezas. Lidas em conjunto, a mensagem, que se apoiavam nos textos das Sagradas

representações do Príncipe Perfeito. In: MENDONÇA, Manuela (dir). O tempo Histórico de D. João II nos 550 anos do seu nascimento (Actas). Lisboa: Academia Portuguesa de História, 2005.

18 Neste grupo identificamos Rubem Junior Amaral em sua: "Emblemática Lusitana e os emblemas de Vasco Mousinho de Castelbranco", Conde de Sabugosa em: "A rainha D. Leonor 1458-1525”, e Virginia Rau no seu: "As empresas e a história das técnicas em Portugal nos séculos XV e XVI". In: Estudos de História Medieval. Lisboa: s/n, s/d.

${ }^{19} \mathrm{O}$ gosto de D. Leonor pelo Evangelho de São Mateus pode ser observado na referência feita ao mesmo no prefácio do "Compromisso do Hospital de Nossa Senhora do Pópulo", de 1512 que se encontra publicado em: PORTUGALIAE MONUMENTA MISERICORDIARUM - volume III: A fundação das Misericórdias: o reinado de D. Manuel I. Centro de Estudos de História Religiosa da Faculdade de Teologia - Universidade Católica Portuguesa; (coord. científico José Pedro Paiva) Lisboa : União das Misericórdias Portuguesas, 2002, pp. 132-151.

\section{8}


Escrituras, transmite o seguinte ideal: O Reino do Céu (o rastro, a rede que pesca todos os homens), lugar da salvação da alma, é a mais preciosa de todas as riquezas ${ }^{20}$ !

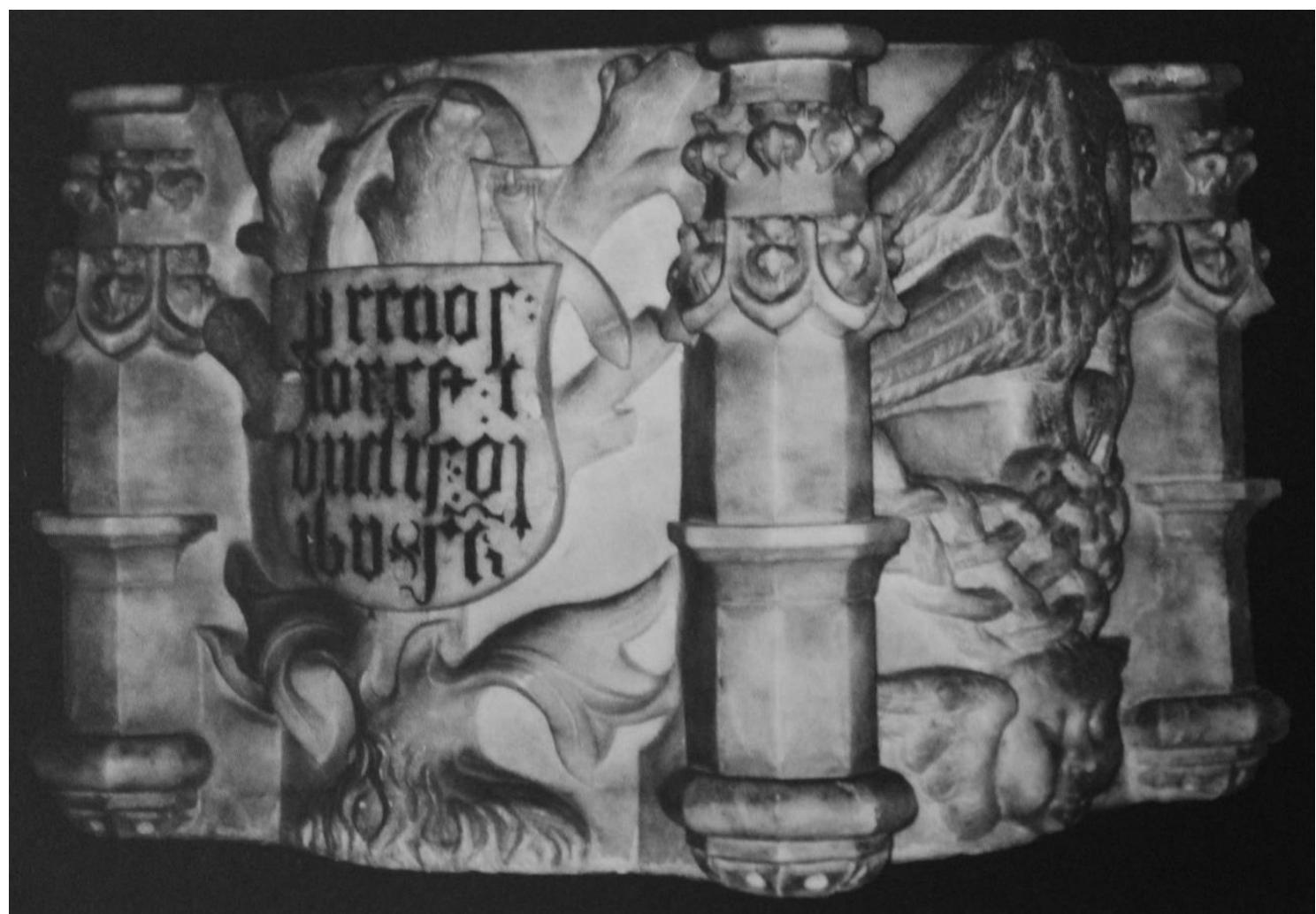

Figura 1: Pia de água benta de D. Leonor.

FONTE: Museu Nacional do Azulejo. Foto de julho de 2013. Arquivo pessoal do autor ${ }^{21}$.

A par de toda a discussão acerca da origem e sentidos interpretativos das divisas e emblemas régios, está claro que eles tinham a função de fazer lembrar e marcar na memória as ações dos monarcas. Esta é uma preocupação evidente da rainha quando tratamos do Hospital de Nossa Senhora do Pópulo. O cuidado com sua memória pode ser vista de maneira muito clara quando, nos "apontamentos" que faz ao bacharel Diogo Diaz para sua viagem de embaixada a Roma para tratar com o cardeal D. Jorge da $\operatorname{Costa}^{22}$.

${ }^{20}$ GALVÃO-TELES, João Bernardo. e SEIXAS, Miguel Metelo de. As insígnias do pelourinho de Óbidos. Subsídios para a compreensão da emblemática da rainha D. Leonor. In: CURVELO, Alexandra. (org). Casa Perfeitíssima. 500 anos da fundação do Mosteiro Madre de Deus. Lisboa: Museu Nacional do Azulejo, 2009.

${ }^{21}$ Agradecemos a gentileza dos técnicos superiores do Museu Nacional do Azulejo, em Lisboa, Alexandre Pires e Alexandra Curvelo por terem nos enviado a imagem da pia batismal e por nos ter esclarecido dúvidas acerca da mesma.

22 "(...) The direes da nosa parte que lhe pedimos muy afetuosamente que por o noso não lhe seja trabalho querer ver de verbo a verbo o trrelado do comprimiso que temos feito pera o espritall da nosa villa das caldas o qual per suas mãaos foy começado e avido com trabalho seu muytas graças que tem E por que 
Além disso, as insígnias e emblemas régios tinham uma função política importante: fazer ver o rei e a rainha mesmo que não estivessem fisicamente presentes. Estamos tratando, neste sentido, de ações e práticas intencionais, construídas pela monarquia para legitimar seu poder por meio de um discurso que usa seus emblemas, insígnias e divisas publicamente. Eram, portanto, formas de representar a monarquia em um momento de gradativa afirmação de seu poder político frente aos poderes locais. Aqui, nas imagens associadas a si, o rei e rainha assumem o seu duplo corpo. Um deles é, como sabemos, o corpo físico, mortal, passível de fraquezas. O outro, o das imagens e das mensagens ligadas a essas. Um corpo que não é divino, nem sagrado (lembremos que os reis de Portugal o são "por graça de Deus"), mas que, ainda assim, não morre uma vez que perpetuado no imaginário coletivo porque é nutrido por essa propaganda das imagens.

\section{Disputas políticas com os poderes locais e o Hospital de Nossa Senhora do Pópulo na afirmação da monarquia no termo de Óbidos}

As imagens se faziam presentes, e com importância política evidente, no espaço em que fora erigido o Hospital de Nossa Senhora do Pópulo. Vale destacar que há uma razão política objetiva para que os monarcas tenham utilizado tempo e recursos na construção do hospital régio na atual Caldas da Rainha. Ali, já há algum tempo, a monarquia portuguesa buscava marcar seu espaço frente ao poder local do Mosteiro de Alcobaça. Este detinha a maior quantidade de terras na região, os chamados coutos de Alcobaça $^{23}$. Iria Gonçalves nos indica que, desde a primeira metade do século XIV, os monarcas tentavam ampliar sua presença na região, inclusive retirando direitos de posse de propriedades do mosteiro ${ }^{24}$. Houve inclusive um período em que o mosteiro esteve sob

nenhuua cousa nossa não queríamos nunca se fose possível fazer sem seu comselho e autoridade $\boldsymbol{E}$ em especiall esta que ha de ficar por nossa memória (grifo nosso) que com tanta devoção e gosto hordenamos lhe emviamos ho dito comprimiso pidindo a sua reverendíssima p. que despois de visto achando nelle alguu erro que não lhe pareça bem rrecebemos em grande e syngullar graça em crelo apontar na maneira que deve hir pera logo ser corregido e tornado a emviarlla E parecendolhe que esta na forma que deve e conpre segundo nossa tenção pera serviço de deos(...)". Texto completo dos “Apontamentos de D. Leonor" se encontra publicado em: SOUZA, Ivo Carneiro de. O cardeal D. Jorge da Costa e a reforma da assistência em Portugal. In: Congresso Internacional Comemorativo do IX Centenário da Dedicação da Sé de Braga: Actas. Braga: Faculdade de Teologia da Universidade Católica Portuguesa/Cabido Metropolitano e Primacial de Braga, N. 2, vol. 1, s/d, pp. 646-660. .

${ }^{23}$ Couto era o termo que se utilizava para referir-se às terras distantes que estavam sob a jurisdição de juízes de determinada localidade. Também era local de envio de devedores e malfeitores.

${ }^{24}$ GONÇALVES, Iria. O patrimônio do mosteiro de Alcobaça nos séculos XIV e XV. Lisboa: Universidade Nova de Lisboa, Faculdade de Ciências Sociais, 1989. p. 350-353. 
a administração de um abade indicado por D. Afonso V (1432-1481). Este abade foi ninguém menos que D. Jorge da Costa, o cardeal de Portugal que, mesmo partindo de sua terra natal em 1480, ainda administrou a Igreja do país por meio de vigários gerais ${ }^{25}$ e que colaborou diretamente para a redação do Compromisso do Hospital de Nossa Senhora do Pópulo.

Podemos, ainda hoje, encontrar as divisas reais, na torre da Igreja, anexa ao hospital, certamente, o lugar mais visível de uma vila que se cria em volta do Hospital e de sua igreja.

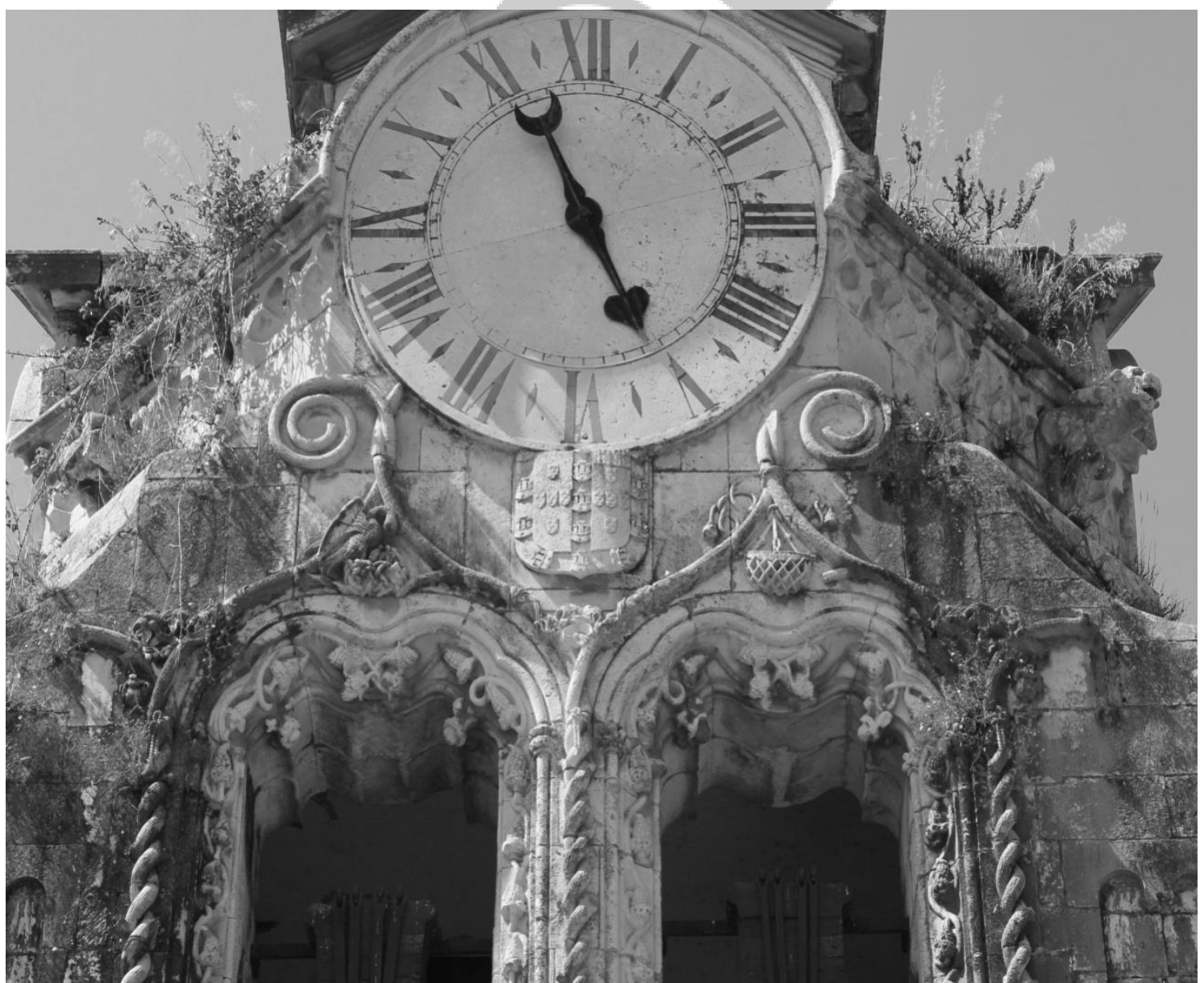

Figura 2: Torre sineira da Igreja de Nossa Senhora do Pópulo.

FONTE: Igreja de Nossa Senhora do Pópulo, nas Caldas da Rainha. Foto do autor em Julho de 2013.

No interior da Igreja, encontramos, mais uma vez, como na torre, as divisas de D. João II e D. Leonor.

${ }^{25}$ VENTURA, Margarida Garcez. “As Visitações Gerais”, de D. Jorge da Costa: notícia e breve análise. Disponível em: < http://ler.letras.up.pt/uploads/ficheiros/4892.pdf >. Acesso em Setembro de 2013. 
Revista Signum, 2017, vol. 18, n. 1.

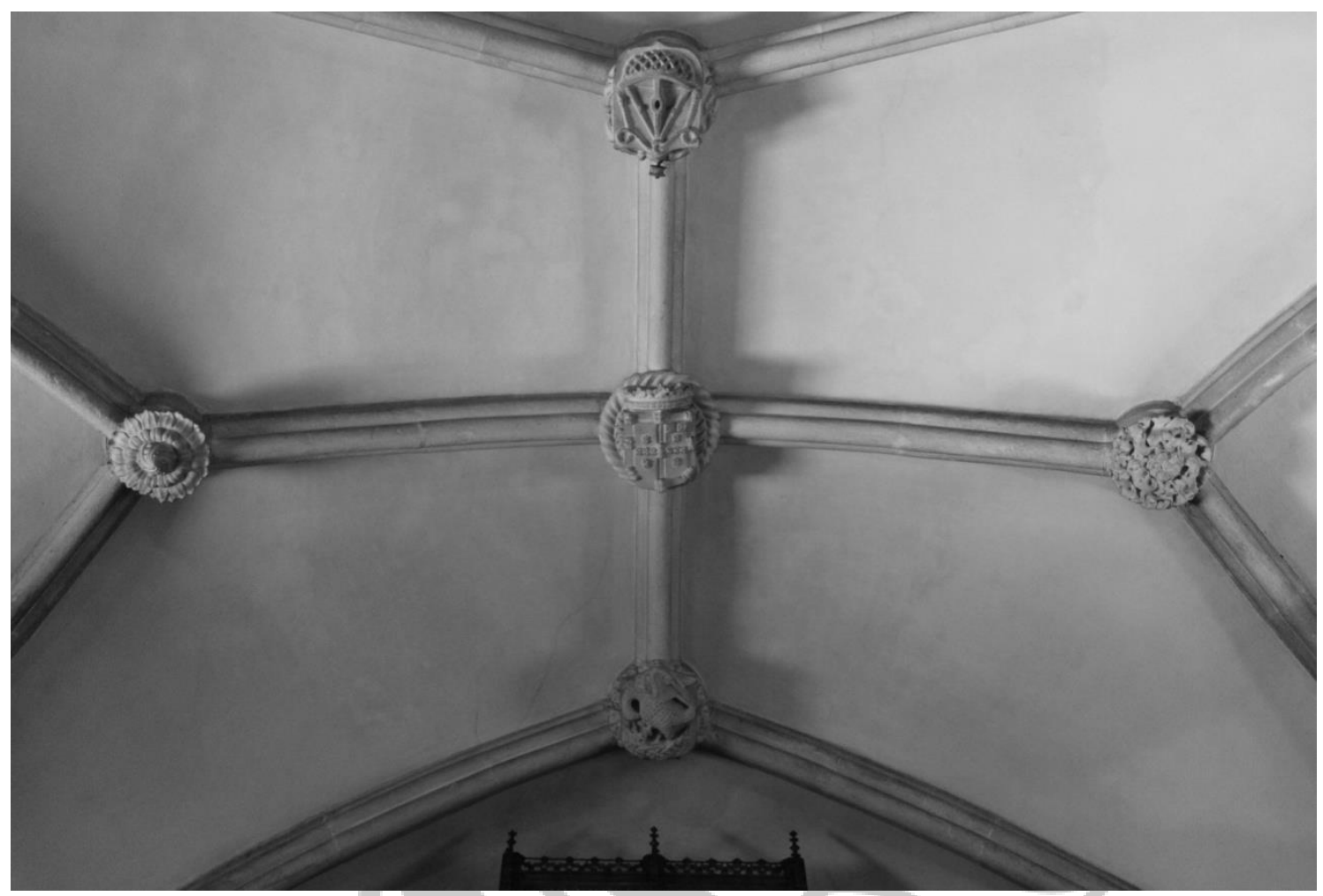

Figura 3: Teto da Igreja de Nossa Senhora do Pópulo.

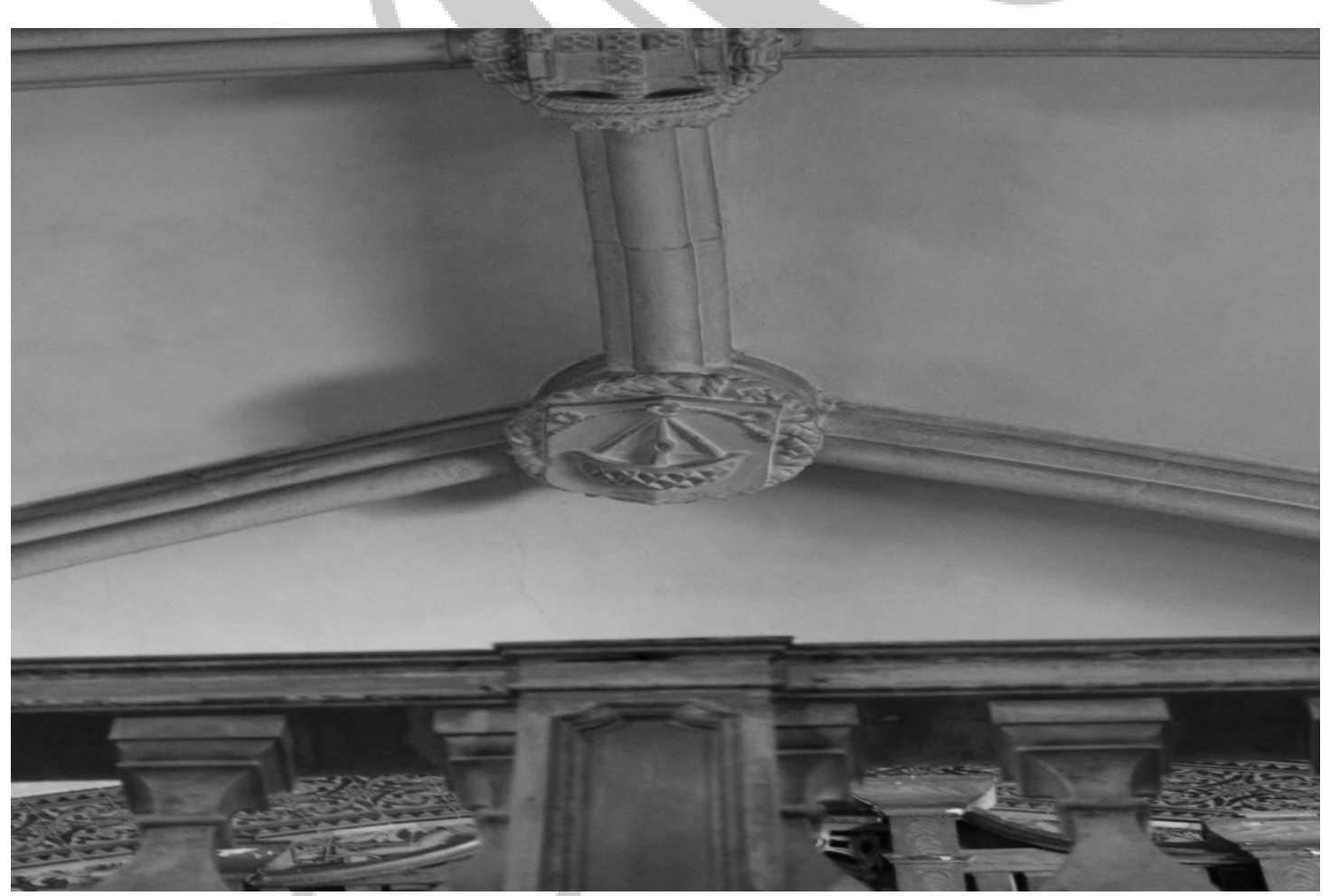

Figura 4: Pormenor do teto da Igreja de Nossa Senhora do Pópulo.

FONTE: Igreja de Nossa Senhora do Pópulo. Foto do autor. Julho de 2013. 
Estamos, portanto, diante de uma situação concreta em que a monarquia - no nosso caso, institucionalizado por meio das propriedades da casa da rainha no termo de Óbidos - tem que marcar sua área de influência e, inclusive, defender suas posses naquele espaço. Destaque-se que, no termo de Óbidos, estamos diante do encontro entre agentes políticos poderosos, nomeadamente os monges de Alçobaça e a monarquia portuguesa. Nunca é demais lembrar que foi do constante encontro de agentes políticos, que pretendiam defender seus interesses, que foi sendo definida a capacidade dos monarcas de governar sobre todo o reino. Portanto, não é sem propósito político que os monarcas investem nesta instituição hospitalar.

Dr. $^{\text {a }}$ Tânia Jorge ${ }^{26}$, do Museu do Hospital e das Caldas, apresentou-nos um documento comprovando que, na origem do Hospital de Nossa Senhora do Pópulo, podemos encontrar o esforço da monarquia portuguesa em avançar na consolidação de seu poder político, evitando, inclusive, que suas posses fossem tomadas por outrem. Há um despacho da Rainha D. Leonor, de 1490, pouco posterior à criação do hospital, em que ela informa saber que:

“(...) nos foy dito que dom abade dalcobaça e seus ofycyaes tomavao e arecadavao os direitos que a nos pertenciam em alguas terras que confrontabao per seus termos e llemjtes e ajnda lançavao maao por allguas terras que as queryao apropriar (...)”27.

A querela entre este mosteiro e a casa da rainha D. Leonor levou à demarcação dos coutos de Alcobaça com o termo de Óbidos no mesmo ano de $1490^{28}$. O mesmo Livro n. 1 do Livro de Registro de Sesmarias do Hospital registra uma cópia desta carta demonstrando a preocupação da rainha com a preservação de suas posses e em firmar a presença da monarquia naquela região da Estremadura.

A preocupação da rainha em salvaguardar o Hospital de Nossa Senhora do Pópulo da tutela da Igreja ou mesmo da nobreza pode ainda ser vista no Compromisso do hospital de 1512. Ao tratar do cargo mais importante, o provedor deixa claro que a administração deveria ser entregue a clérigo ou a leigo que se achar mais preparado para o ofício. A

\footnotetext{
${ }^{26} \mathrm{Dr}^{\mathrm{a}}$. Tânia Jorge é a responsável pelo Museu do Hospital e das Caldas e nos enviou a transcrição com indicação da localização do documento de onde fora retirado este fragmento. Fica nosso agradecimento pelo apoio em todas as ocasiões em que solicitei a ajuda daquela instituição.

${ }^{27}$ Arquivo do Museu do Hospital e das Caldas. Livro de Registro de Sesmarias. Pasta 5, fólio $91 \mathrm{v}$.

${ }^{28}$ A carta com a demarcação dos coutos de Alcobaça com o termo de Óbidos pode ser consultada em: SOUSA, Ivo Carneiro de. A rainha da Misericórdia na História da espiritualidade em Portugal na época do Renascimento. (policopiada). Tese de doutoramento em Cultura Portuguesa. 1992, Universidade do Porto, Vol. 2. pp. 63-73.
} 
rainha não proíbe que a administração do hospital seja de responsabilidade de clérigos. Aliás, a gestão do Hospital foi entregue à Ordem de São João Evangelista, em 1532, por D. João III, e ficou sob sua gestão até a reforma pombalina, em 1722, o que não contrariava em hipótese alguma o texto do Compromisso.

Entretanto impõe uma viva restrição: que não seja “(...) nem frade nem comendador nem pessoa poderosa que passe de cavaleiro para cima (...)"29. Ainda que D. Leonor tivesse o maior apreço pelos franciscanos e ainda que estes pudessem ser os clérigos mais indicados para a administração do Hospital, a rainha buscou evitar a presença efetiva dos frades na gestão do dito hospital. Entendemos que isso indica a clara percepção de que, dada a importância dos franciscanos junto à Coroa, poderia ocorrer a subtração do poder real pela Igreja, por meio da Ordem dos franciscanos naquela região. Ora, se o objetivo não fosse mesmo o de resguardar a influência e a presença do poder régio dentro e a partir do hospital, qual o motivo de também se procurar afastar de sua administração aquela que fosse "pessoa poderosa”? Para nós, está claro que, assim, a coroa não hipotecava a mais ninguém sua influência na região, influência esta conseguida por intermédio de vários meios e de longa data.

A fim de corroborar com esta hipótese, indicaremos dois destes meios. Primeiro que destacamos é a política de povoamento da região através da concessão de privilégios. O interesse da coroa portuguesa na região em que se fundou o hospital se fez maior no reinado de $\mathrm{D}$. Afonso $\mathrm{V}^{30}$.

\footnotetext{
${ }^{29}$ Ver "Compromisso do Hospital de Nossa Senhora do Pópulo de 1512", já citado anteriormente.

${ }^{30}$ Sabemos que $\mathrm{D}$. Afonso $\mathrm{V}$ não foi o primeiro a se preocupar em dar condições de funcionamento àquele local das fontes termais, aliás, já conhecidas desde longa data. O prof. Saul António Gomes defende a tese de que a nobreza já se ocupava de favorecer o local desde, pelo menos, o século XIII e para tanto se refere ao testamento de um tal D. Zouto de 1222. Também se refere ao Compromisso da Gafaria de Santarém que em seu artigo 31 indica que “(...) se gafo ou gafa quiser ir em romaria ou às Caldas, darem-lhe doze dias de ração (...)". Para o século XV temos indícios de que a região possuía estruturas para receber indivíduos para tratamento. João L Saavedra Machado indica o caso de Alvaro Pais (1275 - 1352), bispo de Silves, que, para justificar sua ausência nas Cortes de Santarém, escreve a D. Afonso IV (1291 - 1357) desde o mosteiro da Alcobaça informando que estava em tratamento de uma doença nas Caldas de Óbidos. Também Manuela Santos Silva indica que a infanta D. Isabel $(1397$ - 1471) havia adotado medidas para reorganizar os edifícios existentes nas Caldas, enviando o administrador dos hospitais de suas terras para, com bestas carregadas de materiais, recuperar e administrar os edifícios das ditas caldas. Ver: GOMES, Saul António. As cidades tem uma história: Caldas da Rainha das origens ao século XVIII. Caldas da Rainha: Patrimônio Histórico. 1994.; MACHADO, João L Saavedra. As Caldas: a fundação do hospital e da vila pela rainha D. Leonor. Aspectos da sua evolução até ao século XVII, In: RODRIGUES, Luís Nuno.; SERRA, João B. e TAVARES, Mario (orgs). Terra de águas: Caldas da Rainha. História e cultura. Caldas da Rainha: Câmara Municipal das Caldas da Rainha, 1993, pp. 39-76.; SILVA, Manuela Santos. Religiosidade, caridade e assistência em lugares do Oeste: tradição e inovação. In: AMORIM, Norberta.; PASSOS, Carla. e PINHO, Isabel, (orgs). D Manuel e a sua época. Acta do III Congresso de Guimarães. Vol.II. Guimarães: Câmara Municipal de Guimarães, 2004, pp. 406 - 418.
} 
Em 26 de Junho de 1474, de Santarém, D. Afonso V concede uma carta de privilégios a quatro homens que quiserem viver nas “(...) caldas que estão acerca da nossa vila de Óbidos (...)”. A estes pretensos moradores do local onde mais tarde se fundou o hospital, eram concedidos privilégios não sem que lhes fossem impostas obrigações. Por obrigação, deveriam se estabelecer no local e para assegurar a permanência destes, com o objetivo de dar apoio aos que iam se curar nos ditos banhos, deveriam também fazer vinha e pomar. Os privilégios eram: não servir em guerras, no carreto de madeira e pedras com seus bois e cavalos, assim como não servir ao Conselho. Também recebiam a isenção do pagamento de peitas, fintas, talhas, de jugada e do oitavo. Eram-lhes assegurados que não lhe fossem tomados “(...) pão, cevada, vinho, palha, roupa, galinhas, gados, nem outra cousa alguma do seu contra sua vontade, e fiquem quites e livres de toda servidão Nossa e do dito Concelho(...)"31.

Apesar de esta ser a primeira ocasião em que podemos observar a preocupação da monarquia em fixar, com a concessão de privilégios, a população naquele espaço, não foi a primeira ocasião em que D. Afonso V favorecia as “caldas de Óbidos”. Miguel Nuno Sirieiro Duarte identificou e publicou em sua tese de mestrado duas cartas de perdão, até então inéditas, em que as multas aplicadas nos casos eram direcionadas para as caldas de Óbidos.

"D. Affonso V [rasgado] daa de perdaan a Affonso Gentyl e Joan Gentyl morador em Grijo da Paraada termo de Brangança, acusados de ferrir Diogo Affonso aí morador por terem pagado cada uu 500reais brancuos par obras de reparamento das Caldas de Obidos (grifo nosso)feyto em S. Roaao da Beyra

[assinatura ilegivel] a fiz em xvi de Outubro Era do naçimento de nosso Senhor Jehsu Christo de mjll iiijc Lx iiij."

"D. Affonso V faz perdaan da justiça reegia de uи ano de degreedo par o couto do Marvaam a Affonso Alvarez, morador em Castelo Branquo acusado de fazer avencas e peitas com alguns homes que era contra a ordenaça reegia deu 800reais brancuos par as Caldas acerca da villa de Obidos (grifo nosso) [assinatura ilegivel] a fez vi dias do mes d Dezembro Era do nacimento de nosso Senhor Jehsu Christo de mjll xxxx Lx iiij em Estremos.32"

Observemos que o documento faz menção a certas "obras de reparamento das Caldas", indício de que, de fato, havia certo tempo que eram conhecidos tanto o lugar das fontes (que lá já se encontrava alguma edificação) assim como as propriedades

\footnotetext{
${ }^{31}$ Este documento se encontra publicado em: CORREIA, Fernando da Silva. Pergaminho das Caldas. Caldas da Rainha: Patrimônio Histórico - Grupo de estudos, 1995.

${ }^{32}$ DUARTE, Miguel Nuno Sirieiro. Uma vila que gravita em redor de uma instituição de assistência: a recuperação do patrimônio urbano do Hospital da Caldas até o ano de 1533. Dissertação de mestrado em Estudos do Patrimonio. Universidade Aberta. 2008. Disponível em: < https:// repositorio aberto.uab.pt/handle/10400.2/695 > Acesso em 14/10/2013.
} 
terapêuticas daquelas. É possível, inclusive, que esta fosse aquela que Manuela Santos Silva se refere terem sido alvo das intenções da infanta D. Isabel e já conhecidas por D. Afonso V. Se assim não fosse, qual seria o motivo de se fazer "reparamento das Caldas"?

De qualquer jeito, independente de qualquer preocupação particular anterior como nos casos referidos de D. Zouto, D. Isabel, ou mesmo de D. Afonso V com as cartas de perdão, foi mesmo em 1474 que se iniciou, de forma mais sistemática, a política de ocupação da região pelos monarcas de Avis.

Depois desta data, a próxima vez em que o lugar recebe a atenção, D. Leonor mandou erguer o Hospital de Nossa Senhora do Pópulo, em 148533. Mandou erguê-lo e logo conseguiu o apoio de seu esposo para levar adiante a construção e povoamento daquele lugar. Em 1488, D. João II expediu outra carta de privilégios, agora para trinta famílias34. Desta quantia, haveria de habitar o espaço, com estes privilégios, 20 outros indivíduos35 todos homiziados36. Desta vez é mantida a obrigação de fazer casa, pomar e vinha, mas os privilégios foram ampliados. Eram lhes assegurados o direto de não servir em guerras, não ser acoutado37, além de receberem uma série de isenções dentre as quais de indica: isenção de sisa dos produtos que venderem aos que forem se curar nas Caldas, isenção de aposentadoria (obrigação de dar aposento a alguém em sua casa), isenção do pagamento de portagem, costumagem e de direitos e tributos do que venderem nas Caldas.

Há uma diferença importante entre os dois documentos. Trata-se da relação que estes privilegiados tinham com os doentes que ali iam se tratar. Enquanto no primeiro caso deviam dar apoio aos que ali iam se curar, no segundo caso, essa obrigação não é

\footnotetext{
${ }^{33} \mathrm{~A}$ data de 1485 não é aceite de forma unanime como marco da fundação do hospital. Todavia preferimos seguir de perto a datação que Jorge de São Paulo indica em sua obra.

${ }^{34}$ Encontra-se publicada por CORREIA. Fernando da Silva. Pergaminhos das Caldas. Caldas da Rainha: Patrimonio Histórico - Grupo de Estudos, 1995. pp. 5-8. Existem outras publicações, mas utilizamos esta já que foram feitas as correções ortográficas necessárias.

${ }_{35}$ Estes privilégios foram confirmados posteriormente por D. Manuel em 1497 e mais uma vez em 1512 conforme podemos ver no Primeiro Livro de Notas - Tombo do Hospital. Museu do Hospital e das Caldas. Primeiro Livro de Notas - Tombo do Hospital. MCH - HDL - BA01, fólios 23-26v e 37-38v.

${ }^{36}$ Homiziados eram indivíduos condenados que receberam o perdão real, mas têm que habitar em certa região por determinação real, em geral espaços onde a fixação de população se fazia mais difícil. Em um trabalho acerca do couto dos homiziados a prof. Margarida Garcez Ventura nos lembra que esta foi uma prática útil mas que nem sempre era bem recebida pela população que havia de recepcionar o homiziado. Todavia veremos que, no caso das Caldas da Rainha, esta foi a prática utilizada pela monarquia para assegurar um número mínimo de pessoas na região para que fosse possível dar apoio aos enfermos que iam às fontes termais da região em que fora erigido o hospital. Sobre o couto dos homiziados ver: VENTURA, Margarida Garcez. Os coutos de homiziados nas fronteiras com direito de asilo. Revista da Faculdade de Letras - História. Lisboa: N. 15, vol. 1, 1998, pp. 601-626.

${ }^{37}$ Segundo Bluteau, coutado significa não ser enviado para locais distantes por força de justiça. Disponível em : < http://www.brasiliana.usp.br/en/dicionario/1/acoutado > Acesso em 09/02/2015.
}

\section{6}


mencionada. De certo por que isso já não era uma obrigação imperiosa, uma vez que o primeiro edifício do hospital devia estar em construção e com possibilidade de dar aposentadoria aos doentes. Pelo que pudemos observar, por meio das constantes renovações de privilégios pelos monarcas, a política de povoamento desta região por meio do couto de homiziados tornou-se quase uma regra durante o século posterior a criação do hospital. Em conjunto a esta pratica é de se notar que a autonomia financeira do hospital também era assegurada.

O Compromisso de 1512 já nos indicou, em parte, a origem dos recursos. Aliás, D. Leonor já havia feito doação ao hospital em 150838 de rendas e direitos comprados do seu irmão, o rei D. Manuel I em 1503, e o Compromisso só veio a confirmar tal situação. O Primeiro Livro de Notas - Tombo do Hospital39, à guarda do Museu do Hospital e das Caldas, terminado em 22 de março de 1588, faz um levantamento de toda a fazenda que o hospital tem, em especial dos bens de raiz, em seu termo e fora dele, indicando que a instituição detinha fontes de financiamento que lhe asseguravam sua manutenção e sustento.

O segundo meio que visava garantir seja a autonomia da instituição hospitalar, seja o lugar de memória da coroa, foi a preocupação em dar certa independência espiritual ao hospital desde sua origem. Sendo o tratamento espiritual o primeiro passo para a obtenção da cura, este foi um importante passo na direção da autonomia do hospital frente a qualquer tipo de ingerência externa. A rainha D. Leonor fez questão de assegurar esta independência não apenas com o apoio do episcopado de Lisboa, mas diretamente a Roma. Por meio de uma série de súplicas dirigidas ao Sumo Pontífice, a rainha solicitou uma série de privilégios que vão desde a concessão de indulgências aos que trabalharam na construção do hospital, mas também aos que estavam em artigo de morte, aos que deixassem bens ao hospital, assim como ao direito de indicar o capelão da Igreja de Nossa Senhora do Pópulo sem que este estivesse sob a jurisdição do pároco de Óbidos40. O direito de indicar o capelão veio por bula do papa Alexandre VI, em setembro de 1496.

\footnotetext{
${ }^{38}$ Veja a carta de doação de D. Leonor de 1508, acima referida, publicada em CARVALHO. Augusto da Silva. Memórias das Caldas da Rainha (1484-1884). Lisboa. Tip. da Livraria Ferin, 1932. pp.300-303..

39 Tanto este livro como ainda outros encontram-se digitalizados pelo autor e podem se cedidas por quem solicitar.

40 As súplicas e bulas papais referentes estão publicasdas em: COSTA, António Domingues Sousa. Hospitais e Albergarias na documentação pontifícia da segunda metade do século XV. In: A pobreza e a assistência aos pobres na Península Ibérica durante a Idade Média, Actas das Primeiras Jornadas LusoEspanholas de História Medieval (vol.1), Lisboa: Instituto de Alta Cultura, 1973. pp. 309 - 311.
} 
Esteve assegurada, a partir de então, não apenas o privilégio de D. Leonor em indicar capelão, mas ali se firmava a presença régia, frente ao poder local dos religiosos de Alcobaça e Óbidos, por meio do próprio papado que cedeu à rainha um direito que era do clero.

O caso em estudo é exemplo da construção de marcos referenciais, como os dos que se denominam "lugares de memória", como as insígnias, a Misericórdia de Lisboa e o Hospital de Nossa Senhora do Pópulo. Com a construção, por exemplo, das Crônicas dos reis, da Misericórdia e do hospital nas Caldas da Rainha foram definidos todo um referencial em que se travou uma batalha em torno da imagem da monarquia e cujo objetivo era atingir o imaginário social e redefinir as identidades coletivas. Trata-se, em última instância, do que se observa na construção de representações evidenciadas na luta pelo controle da imaginação social, na manipulação de uma memória e, por consequência, no estabelecimento de uma "memória oficial" e dos comportamentos e atividades individuais e coletivas.

Ao mesmo tempo, em um período em que se processou a afirmação do poder régio frente aos poderes locais ou regionais, a monarquia foi useira e vezeira de instrumentos (imagens e práticas) que pretendiam manipular a memória coletiva objetivando legitimar seu poder e promover a visão de governantes que administravam para seu povo, como o hospital e Igreja fundados por D. Leonor, que eram da invocação “do Pópulo”, do povo. 